\title{
Erratum to: Dynamic life cycle assessment: framework and application to an institutional building
}

\author{
William O. Collinge • Amy E. Landis • Alex K. Jones • \\ Laura A. Schaefer • Melissa M. Bilec
}

Published online: 23 January 2013

(C) Springer-Verlag Berlin Heidelberg 2013

\section{Erratum to: Int J Life Cycle Assess \\ DOI 10.1007/s11367-012-0528-2}

Correction: The legends of Figs. 3 and 5 are corrected as follows:

The online version of the original article can be found at http://dx.doi.org/ 10.1007/s11367-012-0528-2.

\section{W. O. Collinge $\cdot$ M. M. Bilec $(\square)$}

Department of Civil and Environmental Engineering,

University of Pittsburgh, 3700 O'Hara Street,

Pittsburgh, PA 15260, USA

e-mail: mbilec@pitt.edu

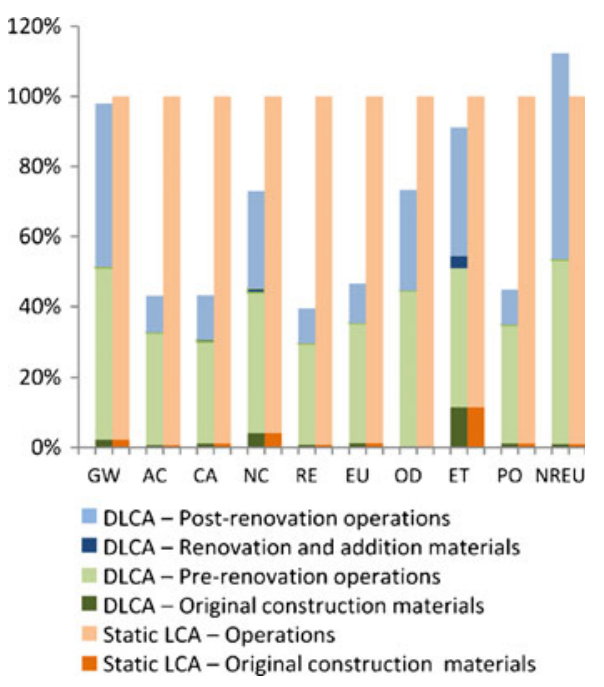

Fig. 3 Comparison of results from static and DLCA models, using the TRACI method. Results are normalized to the total static LCA results for each category. Static LCA results were calculated as the total of the initial construction and projection of the initial year's operating energy consumption for the 75-year life of the building. DLCA results are classified into four categories: original construction materials; prerenovation operations (operating energy consumption through 2008); renovation and addition materials; and post-renovation operations (operating energy consumption 2009 through end of lifetime). $G W$ global warming potential, $A C$ acidification potential, $C A$ human health cancer effects, $N C$ human health noncancer effects, $R E$ human health respiratory effects, $E U$ eutrophication, $O D$ ozone depletion potential, ET ecotoxicity, $P O$ photochemical smog, NREU nonrenewable energy use

\section{A. E. Landis}

School of Sustainable Engineering and the Built Environment, Arizona State University, P.O. Box 875306, Tempe, AZ 85287-5306, USA

\section{A. K. Jones}

Department of Electrical and Computer Engineering,

University of Pittsburgh, Pittsburgh, PA, USA

\section{A. Schaefer}

Department of Mechanical Engineering and Materials Science, University of Pittsburgh, Pittsburgh, PA, USA 


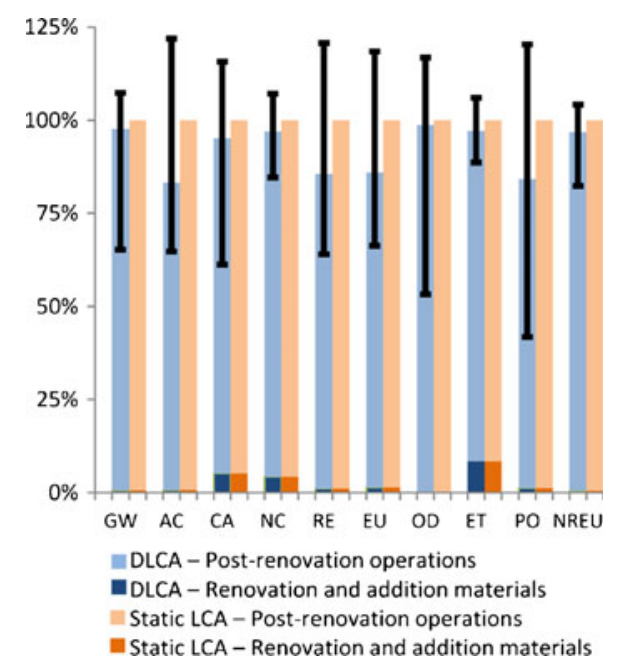

Fig. 5 Comparison of predicted results from static and DLCA models for the renovation and post-renovation operations. Error bars on the DLCA results indicate the minimum and maximum values obtained through the sensitivity analysis. For the GW and PO categories, the error bars include consideration of dynamic characterization factors at the impact assessment step. Error bars for all other categories include only variation in the life cycle inventory. $G W$ global warming potential, $A C$ acidification potential, $C A$ human health cancer effects, $N C$ human health noncancer effects, $R E$ human health respiratory effects, $E U$ eutrophication, $O D$ ozone depletion potential, $E T$ ecotoxicity, $P O$ photochemical smog, NREU nonrenewable energy use 